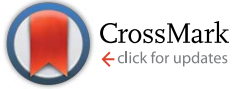

Cite this: Nanoscale, 2014, 6, 9646

Received 8th September 2013 Accepted 12th June 2014

DOI: $10.1039 / c 3 n r 04793 h$

www.rsc.org/nanoscale

\section{Iron oxide nanoparticles stabilized with dendritic polyglycerols as selective MRI contrast agents $\dagger$}

\author{
Daniel Nordmeyer, ${ }^{\text {a }}$ Patrick Stumpf, ${ }^{\text {a }}$ Dominic Gröger, ${ }^{\text {b }}$ Andreas Hofmann, ${ }^{a}$ \\ Sven Enders, ${ }^{c}$ Sebastian B. Riese, ${ }^{\mathrm{C}}$ Jens Dernedde, ${ }^{\mathrm{C}}$ Matthias Taupitz, ${ }^{\mathrm{d}}$ Ursula Rauch, ${ }^{\mathrm{e}}$ \\ Rainer Haag, ${ }^{\star b}$ Eckart Rühl $^{\star a}$ and Christina Graf ${ }^{\star a}$
}

\begin{abstract}
Monodisperse small iron oxide nanoparticles functionalized with dendritic polyglycerol (dPG) or dendritic polyglycerol sulfate (dPGS) are prepared. They are highly stable in aqueous solutions as well as physiological media. In particular, oleic acid capped iron oxide particles (core diameter $=11 \pm 1 \mathrm{~nm}$ ) were modified by a ligand exchange process in a one pot synthesis with dPG and dPGS bearing phosphonate as anchor groups. Dynamic light scattering measurements performed in water and different biological media demonstrate that the hydrodynamic diameter of the particles is only slightly increased by the ligand exchange process resulting in a final diameter of less than $30 \mathrm{~nm}$ and that the particles are stable in these media. It is also revealed by magnetic resonance studies that their magnetic relaxivity is reduced by the surface modification but it is still sufficient for high contrast magnetic resonance imaging (MRI). Additionally, incubation of dPGS functionalized iron oxide nanoparticles with human umbilical vein endothelial cells showed a $50 \%$ survival at $85 \mathrm{nM}$ (concentration of nanoparticles). Surface plasmon resonance (SPR) studies demonstrate that the dPGS functionalized iron oxide nanoparticles inhibit L-selectin ligand binding whereas the particles containing only dPG do not show this effect. Experiments in a flow chamber with human myelogenous leukemia cells confirmed L-selectin inhibition of the dPGS functionalized iron oxide nanoparticles and with that the L-selectin mediated leukocyte adhesion. These results indicate that dPGS functionalized iron oxide nanoparticles are a promising contrast agent for inflamed tissue probed by MRI.
\end{abstract}

\section{Introduction}

Magnetic nanoparticles, especially iron oxide particles in the size regime of 3 to $50 \mathrm{~nm}$, have been frequently used for many

${ }^{a}$ Physikalische Chemie, Institut für Chemie und Biochemie, Freie Universität Berlin, Takustr. 3, 14195, Berlin, Germany.E-mail: ruehl@zedat.fu-berlin.de; cmgraf@ zedat.fu-berlin.de; Fax: +49 30 83852217; +49 30838 56263; Tel: +49 30 83852396; +493083855304

${ }^{b}$ Organische Chemie, Institut für Chemie und Biochemie, Freie Universität Berlin, Takustr. 3, 14195, Berlin, Germany. E-mail: haag@chemie.fu-berlin.de; Fax: +49 30 83852633; Tel: +493083853357

'Charité - Universitätsmedizin Berlin, Institut für Laboratoriumsmedizin, Klinische Chemie und Pathobiochemie, Campus Virchow Klinikum, Augustenburger Platz 1, 13353 Berlin, Germany

${ }^{d}$ Charité Centrum für Herz-, Kreislauf- und Gefäßmedizin 11, Med. Klinik II, CharitéUniversitätsmedizin Berlin, Campus Benjamin Franklin, Hindenburgdamm 30, 12200 Berlin, Germany

'Institut für Radiologie, Charité - Universitätsmedizin Berlin, Campus Charité Mitte, Charitéplatz 1, 10117 Berlin, Germany

$\dagger$ Electronic supplementary information (ESI) available: A detailed description of the synthesis of the ligands as well as the preparation and functionalization of the iron oxide nanoparticles including their physico-chemical characterization are presented. Further, details of the cell experiments and the SPR experiments are given. Two representative movies are provided showing leukocyte rolling on the ligand coated surface of the flow chamber. See DOI: 10.1039/c3nr04793h practical applications in materials science, such as magnetic storage devices, ${ }^{1}$ catalysis, ${ }^{2}$ as well as in life sciences for instance in cancer therapy hyperthermia ${ }^{3}$ and magnetic resonance imaging (MRI) ${ }^{4,5}$ since they exhibit a superparamagnetic behavior. Established standard syntheses, such as wet chemical co-precipitation reactions yield hydrophilic but usually polydisperse nanoparticles of about 3-6 $\mathrm{nm} .{ }^{6}$ These systems show a low degree of crystallinity and, as a consequence, they yield a low magnetic response. ${ }^{4,7}$

Small, well defined iron oxide nanoparticles with a narrow size distribution consisting of magnetite $\left(\mathrm{Fe}_{3} \mathrm{O}_{4}\right)$ and maghemite $\left(\gamma-\mathrm{Fe}_{2} \mathrm{O}_{3}\right)$ are of great interest, since magnetic properties change drastically with particle size. ${ }^{4}$ High temperature approaches lead to large amounts of nearly monodisperse iron oxide nanoparticles of excellent stability in hydrophobic media and reproducible magnetic properties, which is unlike to coprecipitation methods. Sun et al. demonstrated in 2004 the formation of hydrophobic iron oxide nanoparticles by heating an iron precursor together with a complexing agent in a high boiling solvent. ${ }^{8}$ In many publications based on this work iron oleate as a non-toxic iron oxide nanoparticle precursor is heated up to the boiling point of the organic solvent., ${ }^{5,9}$ By using a welldefined temperature gradient in these processes, nucleation 
and particle growth are well separated leading to nearly monodisperse, hydrophobic iron oxide nanoparticles in the size regime of 3-20 nm. ${ }^{8}$ However, for biological applications, iron oxide nanoparticles are needed, which are dispersible in aqueous media. In the last decade, different functionalization agents were developed to enhance the colloidal stability of superparamagnetic iron oxide nanoparticles even at physiological salt concentrations. Commercially available iron oxide nanoparticles for MRI are typically small, polydisperse nanoparticles. These are made by co-precipitation forming in physiological media usually larger agglomerates with a hydrodynamic diameter of up to $200 \mathrm{~nm}^{4}{ }^{4}$ These agglomerates are usually decorated by sugars or other polymers and show poor affinity to any specific kind of tissue. ${ }^{8,10}$ For example, Jung et al. presented dextran-functionalized iron oxide nanoparticle agglomerates (Feridex) with a hydrodynamic diameter of 160 nm. ${ }^{11}$ Different approaches based on the implementation of biocompatible coating polymers, such as poly(ethylene glycol) (PEG), ${ }^{12}$ have been proposed to enhance the stability of such nanoparticles. However, many of these ligands lack in functional groups for derivatization. ${ }^{13,14}$ Hervé et al. referred about covalent attaching of polyethylene oxide polymer chains (PEGylation) to iron oxide nanoparticles for biological applications. However, also in this case, the iron oxide particles were synthesized by a co-precipitation process and they are rather polydisperse and polymorphous. Additionally, the large size of the partial aggregated particles and the large size of the polymer ligand causes a significant increase in hydrodynamic diameter (about $82 \mathrm{~nm}$ ), limiting their use for biological applications. ${ }^{12}$ Furthermore, nanoparticles smaller than $50 \mathrm{~nm}$ have the potential for lymph-node-imaging, ${ }^{15,16}$ angiography, ${ }^{4}$ and functional MRI (f-MRI). ${ }^{4}$ Therefore, the hydrophilic functionalization of well-defined small and non-aggregated particles from high-temperature synthesis appears to be more promising. Gu et al. decorated iron oxide particles from high-temperature synthesis with porphyrin and observed their cellular uptake. The core diameter of these particles was about $10 \mathrm{~nm}$ but the hydrodynamic diameter was not reported and leads to questions regarding the stability of the particles. ${ }^{17} \mathrm{Xie}$ et al. reported the functionalization of oleate-capped iron oxide particles with human serum albumin. The obtained particles have a hydrodynamic diameter of about $29 \mathrm{~nm}$ and they are stable for $48 \mathrm{~h}$ at $37{ }^{\circ} \mathrm{C}$ in phosphate buffered saline. ${ }^{18}$ Hofmann et al. ligandexchanged oleate-capped $\mathrm{Fe}_{3} \mathrm{O}_{4}$ nanoparticles with multifunctional dendron ligands. ${ }^{5}$ The particles are highly stable in physiological media and not toxic but cannot target, as well as the particles mentioned above, to a specific tissue. Recently, Zhou et al. reported the synthesis of iron oxide nanoparticles conjugated to the human monoclonal antibody PGN635, which specifically bind to phosphatidylserine which is present on the surface of endothelial cells in tumor vasculature, but not in normal blood vessels. ${ }^{19}$ However, a detailed study of the colloidal stability and the surface functionalization of these particles was not provided. Therefore, developing suitable water-soluble biocompatible ligands for the stabilization of iron oxide nanoparticles with affinity to a certain kind of tissue became a central issue within the emerging field of nanomedicine. ${ }^{10,20}$ Additionally, nanoparticles for biological applications should be decorated with "stealth"-ligands leading to long blood circulation times. Therefore, achieving in one system selectivity towards binding to a defined tissue and demonstrating at the same time an acceptable biocompatibility including long blood circulation times, low accumulation and excretion are main challenges in modern contrast agent development.

Multifunctional dendritic polyglycerol (dPG), based on a soft polyether polyol scaffold, is known to be highly biocompatible and suitable for biomedical applications $\mathrm{s}^{21,22}$ and has found its use in various applications. ${ }^{21}$ Besides its protein and cell resistant properties, ${ }^{21,23-25}$ dPG-based ligands are known to strongly enhance water solubility and have been used to functionalize e.g. dyes, ${ }^{26}$ proteins, ${ }^{27}$ or gold nanoparticles. ${ }^{28}$ Functionalized dendritic ligands are known for their excellent binding properties. Gillich et al. recently demonstrated for poly(ethylene glycol) ligands with multivalent catechol groups that dendritic macromolecular ligands with a comparatively smaller and more confined molecular volume in comparison to their linear analogue allow for a more efficient binding to the surface and hence a higher stability in biologically relevant high-ionic-strength buffer solutions. ${ }^{29}$ The sulfated analogue of dPG, dendritic polyglycerol sulfate (dPGS) was introduced in 2004 as a fully synthetic, biocompatible polymer with moderate anticoagulant and strong antiinflammatory properties. $^{30}$ The anti-inflammatory activity of dPGS in vivo is based on binding to certain blood proteins e.g. complement factors C3 and C5 and its exceptional high binding affinity towards the cell adhesion glycoproteins L-selectin, expressed on leukocytes and P-selectin, present on platelets and activated endothelia. Thus, massive leukocyte extravasation as detected in acute and chronic inflammatory diseases is reduced by dPGS through inhibition of complement activation and blockade of the leukocyte adhesion cascade. ${ }^{31-34}$ Exploiting this multitarget binding allows for the design of inflammation-specific dPGS-based probes, as recently shown for a dPGS near-IR conjugate targeting arthritis in a rat model $^{35}$ and demonstrated for dPGS coated Au NP applied for optical imaging of arthritis in a mouse model. ${ }^{36}$ Wang et al. recently functionalized iron oxide nanoparticles with $\mathrm{dPG}^{37}$ These particles were highly stable in cell culture media, showing no cytotoxicity towards mammalian cells, and a low uptake by macrophages. However, the functionalization of these particles with dPG is achieved by a laborious stepwise synthesis and notably these particles do not show any selectivity regarding binding to a specific kind of tissue. In this "grafting-from" synthesis a further functionalization of the nanoparticles is difficult because they do not remain stable, e.g. in acids. ${ }^{5}$ In contrast, in a "grafting to" approach, nanoparticles and polymer-ligands can be attached to each other in the last step by ligand exchange and no additional chemistry with the iron oxide nanoparticles is required. Particles and ligands can be independently characterized in advance. Therefore, using dPGS based ligands for nanoparticle functionalization represents a feasible "grafting to" approach for the formation of biocompatible hybrid MRI contrast agents. 
Here, we present a novel simple one-pot approach for the functionalization of small monodisperse oleic acid capped iron oxide nanoparticles from a high temperature approach with dPG and dPGS. The stability of these systems is investigated in water and in several physiological media. Further, the magnetic relaxivity as a measure for their magnetic contrast is studied before and after polyglycerol functionalization. Cytotoxicity studies are carried out to investigate whether the particles are suitable for in vivo applications. Additionally, surface plasmon resonance spectroscopy measurements are performed which reveal that the L-selectin binding to immobilized ligands is drastically reduced in vitro by the selective and competitive binding of dPGS but not dPG decorated iron oxide nanoparticles. Finally, a flow cell assay with human myelogenous leukemia cells confirmed L-selectin inhibition of the dPGS functionalized iron oxide nanoparticles and with that the L-selectin mediated leukocyte adhesion.

\section{Results and discussion}

Monodisperse superparamagnetic iron oxide nanoparticles were synthesized as described before by a high temperature approach using iron oleate in 1-octadecene (see Scheme 1). ${ }^{38}$ The synthesized nanoparticles were purified by repeated sedimentation/redispersion cycles to remove by-products and 1-octadecene. After purification the resulting nanoparticles,
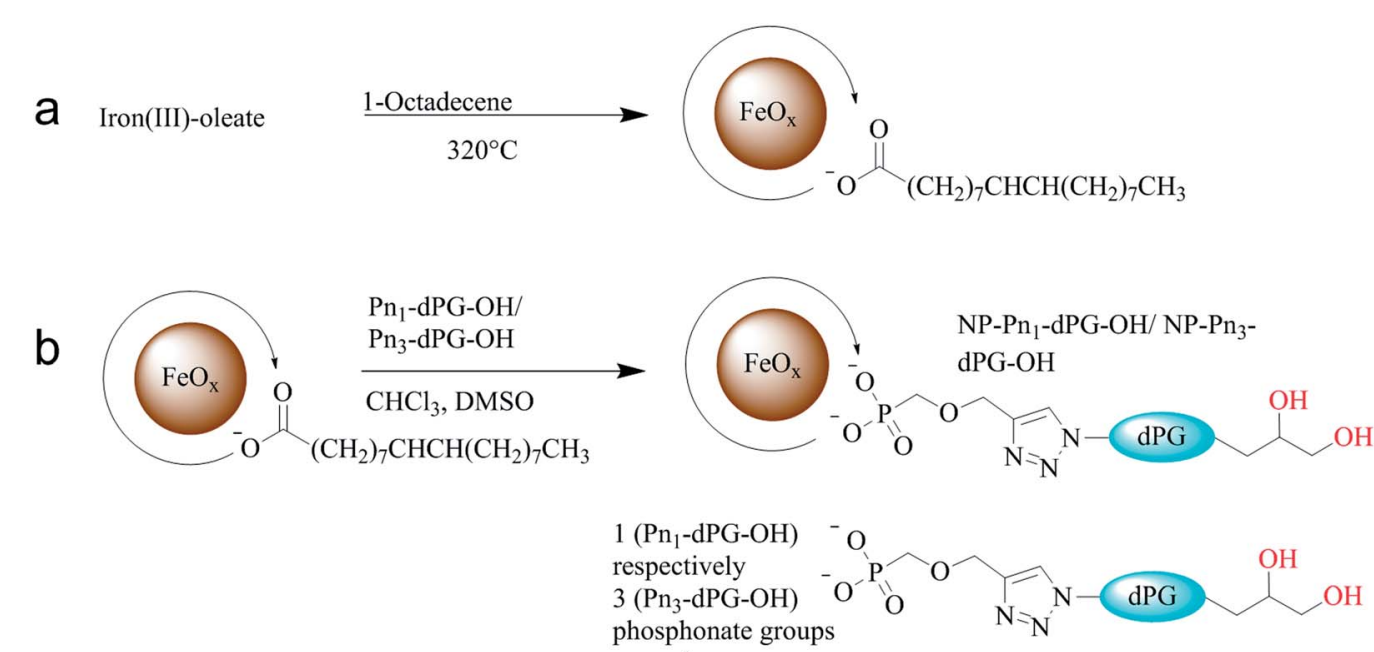

$$
\text { per polymer }
$$
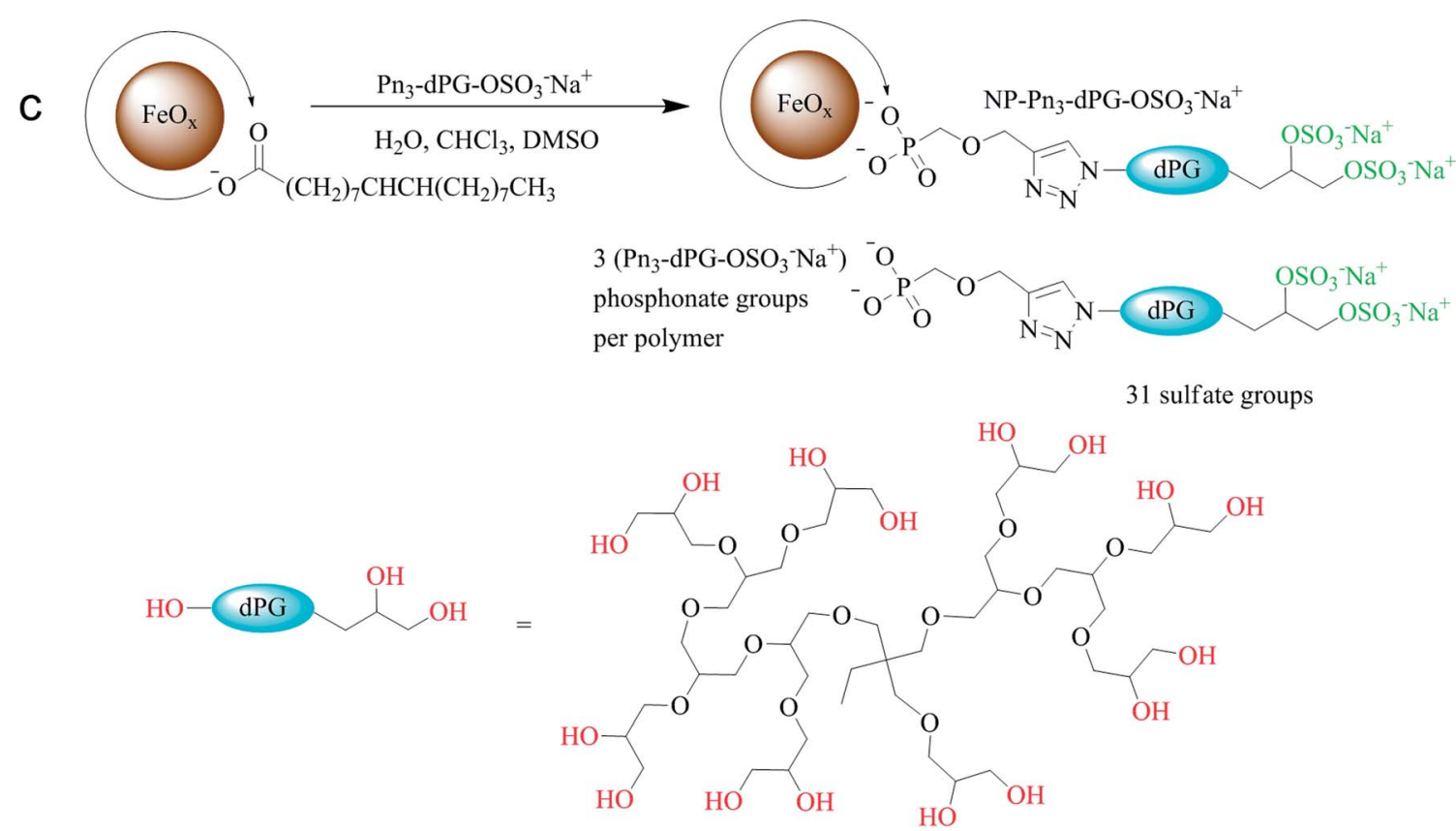

Scheme 1 (a) Synthesis of oleate functionalized iron oxide nanoparticles. Functionalization of oleate coated iron oxide nanoparticles (b) with dendritic polyglycerol (dPG) or (c) with dendritic polyglycerol statistically functionalized with $76 \%$ (=31) sulfate end groups (dPGS). The polyglycerol ligands contain about one $\left(\mathrm{Pn}_{1}-\mathrm{dPG}-\mathrm{OH}\right)$ or three $\left(\mathrm{Pn}_{3}-\mathrm{dPG}-\mathrm{OH}, \mathrm{Pn}_{3}-\mathrm{dPG}-\mathrm{OSO}_{3}{ }^{-} \mathrm{Na}^{+}\right)$phosphonate linker groups, respectively. The chemical structure of the dPG scaffold is representative. The molar mass of the dPG unit in all experiments was about $3000 \mathrm{~g}$ mol ${ }^{-1}$. 
Table 1 DLS data of iron oxide nanoparticles functionalized by oleate, $\mathrm{Pn}_{1}-\mathrm{dPG}-\mathrm{OH}, \mathrm{Pn}_{3}-\mathrm{dPG}-\mathrm{OH}$, and $\mathrm{Pn}_{3}-\mathrm{dPG}^{-} \mathrm{OSO}{ }_{3}^{-} \mathrm{Na}^{+}$, and $\mathrm{Resovist}^{\circledR}$ in chloroform, ultrapure water, isotonic saline, and DMEM/FCS/P/S (Dulbecco's Modified Eagle Medium (DMEM) with 10\% fetal calf serum (FCS), penicillin (P), 100 units per $\mathrm{mL}$ ), and streptomycin (S, $100 \mu \mathrm{g} \mathrm{mL}{ }^{-1}$ )

\begin{tabular}{|c|c|c|c|c|}
\hline \multirow[b]{2}{*}{ Sample } & \multirow[b]{2}{*}{ Surface } & \multicolumn{3}{|c|}{ Hydrodynamic diameter $[\mathrm{nm}]$ in } \\
\hline & & $\mathrm{CHCl}_{3}{ }^{\mathrm{a}} /$ ultrapure water ${ }^{\mathrm{b}}$ & Isotonic saline & DMEM/FCS/P/S \\
\hline NP-OA & $\mathrm{OA}$ & $14 \pm 2^{\mathrm{a}}$ & - & - \\
\hline $\mathrm{NP}-\mathrm{Pn}_{1}$-dPG-OH & $\mathrm{Pn}_{1}$-dPG-OH & $45 \pm 1^{\mathrm{b}}$ & - & - \\
\hline $\mathrm{NP}-\mathrm{Pn}_{3}$-dPG-OH & $\mathrm{Pn}_{3}-\mathrm{dPG}-\mathrm{OH}$ & $26 \pm 2^{b}$ & $28 \pm 2$ & $23 \pm 1$ \\
\hline NP-Pn ${ }_{3}-\mathrm{dPG}-\mathrm{OSO}_{3}{ }^{-} \mathrm{Na}^{+}$ & $\mathrm{Pn}_{3}$-dPG-OSO ${ }_{3}^{-} \mathrm{Na}^{+}$ & $24 \pm 1^{b}$ & $23 \pm 1$ & $20 \pm 13$ \\
\hline Resovist $₫$ & Carboxy-dextran & ca. $60^{\mathrm{b}}$ & - & - \\
\hline
\end{tabular}

sample NP-OA, are dispersible in organic solvents, such as hexane and chloroform and present high colloidal stability in these media (see Table 1). The particles have a core diameter of $(11 \pm 1) \mathrm{nm}$, as obtained from transmission electron microscopy (TEM) measurements. Their hydrodynamic diameter of $(14 \pm 2) \mathrm{nm}$ is slightly larger. TEM imaging (Fig. 1a) shows spherical, monodisperse, separated, and not aggregated particles. The hydrodynamic diameter of sample NP-OA is slightly enlarged compared to the core diameter because of the extension of the oleate-groups and the solvent shell. Via a ligand exchange process polar ligands can be introduced, leading to water-dispersity of the particles. Therefore, two dendritic polyglycerol with one $\left(\mathrm{Pn}_{1}-\mathrm{dPG}-\mathrm{OH}\right)$ or three $\left(\mathrm{Pn}_{3}-\mathrm{dPG}-\mathrm{OH}\right)$ phosphonate (Pn) binding sites and one dendritic polyglycerol sulfate with three phosphonate binding sites $\left(\mathrm{Pn}_{3}-\mathrm{dPG}\right.$ $\mathrm{OSO}_{3}{ }^{-} \mathrm{Na}^{+}$) were introduced.

$\mathrm{Pn}_{1}$-dPG-OH and $\mathrm{Pn}_{3}$-dPG-OH with a PD of $<1.7$ and a number average in molecular weight of $M_{\mathrm{n}}=3000 \mathrm{~g} \mathrm{~mol}^{-1}$ provides about 40 polar hydroxyl groups and $\mathrm{Pn}_{3}$-dPG$\mathrm{OSO}_{3}{ }^{-} \mathrm{Na}^{+}$contains about 31 sulfate groups per polymer leading to high water solubility (see Scheme 1). The phosphonate groups represent the anchor for the iron oxide. ${ }^{10}$ The plenty of hydroxyl or sulfate groups provide a high hydrophilicity and the multifunctional dPG polymer allows for conjugation to other molecules such as dyes, ${ }^{26}$ antibodies, and proteins ${ }^{39}$ to the nanoparticles in future studies. Multivalent ligands with more than one phosphonate binding site per polymer have a stronger binding affinity than the monovalent ones. ${ }^{29,40}$ For this reason, we investigate, if dPG ligands with three instead of one phosphonate group lead to iron oxide nanoparticles of higher colloidal stability. Increasing the number to more than three phosphonate groups per polymer, however, leads to aggregation and crosslinking of the iron oxide particles resulting in precipitation.

The ligand exchange process was carried out by mixing purified oleate-stabilized iron oxide nanoparticles with $\mathrm{Pn}_{1}$ dPG-OH, $\mathrm{Pn}_{3}$-dPG-OH in a $1: 0.23$ mixture of chloroform and DMSO and in the case of $\mathrm{Pn}_{3}-\mathrm{dPG}^{-} \mathrm{OSO}_{3}{ }^{-} \mathrm{Na}^{+}$in a $1: 0.33: 0.22$ mixture of chloroform, DMSO, and ultrapure water (see Scheme 1). Using these solvents a monophasic system is achieved, leading to maximum mixing of ligands and nanoparticles. By using a two phase system, containing ultrapure water and chloroform as solvents, no significant reaction occurs at the interface and the particles remain oleate functionalized.

After the ligand exchange process, the iron oxide nanoparticles were washed three times with ethyl acetate to remove NP-OA and DMSO. Subsequently, the precipitated particles were dried in an argon stream to remove ethyl acetate and chloroform and finally, they are redispersed in aqueous media, such as ultrapure water, isotonic saline, or Dulbecco's modified Eagle Medium (DMEM) with 10\% fetal calf serum, penicillin (100 units per $\mathrm{mL})$ and streptomycin $\left(100 \mu \mathrm{g} \mathrm{mL}^{-1}\right)(\mathrm{DMEM} / \mathrm{FCS} / \mathrm{P} / \mathrm{S})$. It is crucial that all harmful substances, such as chloroform are completely removed during the purification process to minimize the cytotoxicity of the nanoparticle dispersion. IR spectroscopy confirms a successful ligand exchange and binding of the
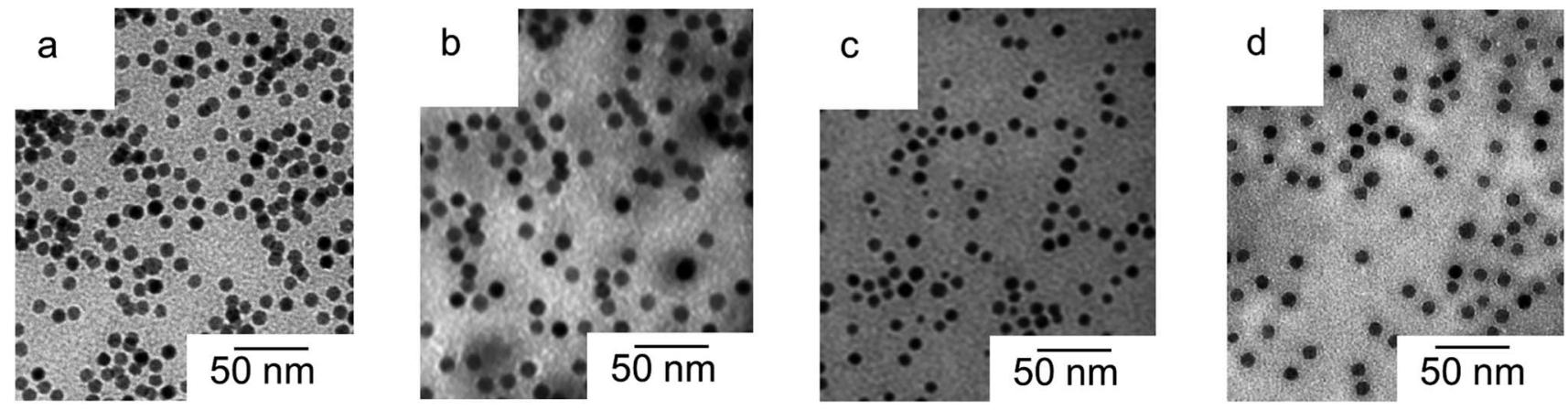

Fig. 1 TEM micrographs of (a) oleic acid-coated iron oxide nanoparticles (sample NP-OA), and (b)-(d) particles functionalized by the dendritic

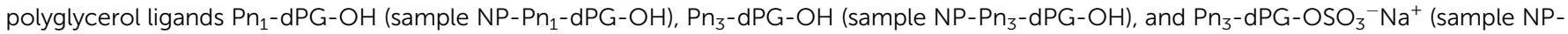
$\mathrm{Pn}_{3}-\mathrm{dPG}-\mathrm{OSO}_{3}{ }^{-} \mathrm{Na}^{+}$. 
phosphonate groups to iron on the surface of the nanoparticles, since a sharp peak at $1018 \mathrm{~cm}^{-1}$ which accounts for superimposed $\mathrm{Fe}-\mathrm{O}-\mathrm{P}$ and $\mathrm{P}=\mathrm{O}$ stretching bands was found in the spectra of the particles after ligand exchange (see Fig. S2 in the ESI $\dagger)^{41,42}$

The iron oxide nanoparticles functionalized with $\mathrm{Pn}_{1}$-dPG$\mathrm{OH}, \mathrm{Pn}_{3}$-dPG-OH and $\mathrm{Pn}_{3}$-dPG-OSO ${ }_{3}{ }^{-} \mathrm{Na}^{+}\left(\mathrm{NP}-\mathrm{Pn}_{1}\right.$-dPG-OH, NP$\mathrm{Pn}_{3}-\mathrm{dPG}-\mathrm{OH}$ and $\mathrm{NP}-\mathrm{Pn}_{3}-\mathrm{dPG}-\mathrm{OSO}_{3}{ }^{-} \mathrm{Na}^{+}$) show colloidal stability in different aqueous media (see Table 1), as proven by dynamic light scattering (DLS) and TEM. NP-Pn ${ }_{3}$-dPG$\mathrm{OSO}_{3}{ }^{-} \mathrm{Na}^{+}$shows a zeta potential of $(-19 \pm 4) \mathrm{mV}$ in ultrapure water which corresponds to the zeta potential of pure dendritic polyglycerol sulfate (dPGS) $(-14 \pm 4) \mathrm{mV}$ within the experimental error. ${ }^{33}$ Besides this moderate electrostatic stabilization in case of the $\mathrm{Pn}_{3}-\mathrm{dPG}-\mathrm{OSO}_{3}{ }^{-} \mathrm{Na}^{+}$-stabilized particles, the high colloidal stability of both samples, NP-Pn $-\mathrm{dPG}-\mathrm{OH}$ and NP-Pn ${ }_{3}$ dPG-OSO ${ }_{3}{ }^{-} \mathrm{Na}^{+}$, can be explained by the spatial extension of both ligands providing a substantial steric stabilization. As a result, the samples with three phosphonate ligands show colloidal stability in ultrapure water for more than one year.

In contrast to sample NP-OA, all particles, functionalized by dendritic polyglycerol cannot be dispersed in organic solvents, such as chloroform and hexane. After functionalization with ligand $\mathrm{Pn}_{1}-\mathrm{dPG}-\mathrm{OH}$, the iron oxide particles are dispersible in ultrapure water where they have a hydrodynamic diameter of $(45 \pm 1) \mathrm{nm}$, indicating that some aggregates are formed (see Table 1).

This observation is in agreement with the TEM results, where small agglomerates are found (see Fig. 1b). Both nanoparticle samples, where a ligand with three phosphonate binding sites $\left(\mathrm{Pn}_{3}-\mathrm{dPG}-\mathrm{OH}\right.$ and $\left.\mathrm{Pn}_{3}-\mathrm{dPG}-\mathrm{OSO}_{3}{ }^{-} \mathrm{Na}^{+}\right)$is used, have a significantly smaller hydrodynamic diameter in water (sample NP-Pn ${ }_{3}$-dPG-OH: $(26 \pm 2) \mathrm{nm}$ and sample NP-Pn ${ }_{3}$-dPG$\left.\mathrm{OSO}_{3}{ }^{-} \mathrm{Na}^{+}:(24 \pm 1) \mathrm{nm}\right)$ than sample NP-Pn ${ }_{1}-\mathrm{dPG}-\mathrm{OH}:(45 \pm 1)$ $\mathrm{nm}$ (see Table 1). Assuming that the extension of the bulky dendritic polyglycerol ligands $\mathrm{Pn}_{3}$-dPG-OH (molar mass $3600 \mathrm{~g}$ $\mathrm{mol}^{-1}$ ) and $\mathrm{Pn}_{3}$-dPG-OSO ${ }_{3}{ }^{-} \mathrm{Na}^{+}$(molar mass $7250 \mathrm{~g} \mathrm{~mol}^{-1}$ ) in water is of the order of 3-4 $\mathrm{nm}$ which corresponds to the hydrodynamic diameter of the free ligands in water. Considering the shell of water molecules around the particles, both DLS results indicate that the particles are not or negligibly aggregated in water in contrast to sample NP-Pn ${ }_{1}$-dPG-OH. This conclusion agrees well with the TEM micrographs shown in Fig. 1(c) and (d), where only single particles separated by a distance of at least $3 \mathrm{~nm}$ are found, corresponding to the

Table 2 Stability ${ }^{a}$ of NP-Pn $-\mathrm{dPG}-\mathrm{OH}$ and NP-Pn$n_{3}-\mathrm{dPG}-\mathrm{OSO}_{3}{ }^{-} \mathrm{Na}^{+}$ in isotonic saline and DMEM/FCS/P/S

\begin{tabular}{|c|c|c|}
\hline \multirow[b]{2}{*}{ Sample } & \multicolumn{2}{|l|}{ Stability $[\mathrm{d}]$} \\
\hline & Isotonic saline & DMEM/FCS/P/S \\
\hline $\mathrm{NP}-\mathrm{Pn}_{3}$-dPG-OH & 4 & 9 \\
\hline $\mathrm{NP}-\mathrm{Pn}_{3}-\mathrm{dPG}-\mathrm{OSO}_{3}{ }^{-} \mathrm{Na}^{+}$ & 5 & 11 \\
\hline
\end{tabular}

Table 3 Relaxation properties ${ }^{a}$ of the iron oxide nanoparticles NP-OA, $\mathrm{NP}-\mathrm{Pn}_{3}-\mathrm{dPG}-\mathrm{OH}$, and NP-Pn$n_{3}-\mathrm{dPG}-\mathrm{OSO}_{3}{ }^{-} \mathrm{Na}^{+}$. The sample NP-OA was measured in chloroform, the samples NP-Pn $3-d P G-O H$ and NP$\mathrm{Pn}_{3}-\mathrm{dPG}-\mathrm{OSO}_{3}{ }^{-} \mathrm{Na}^{+}$were measured in ultrapure water

\begin{tabular}{|c|c|c|c|}
\hline Sample & $r_{1}\left[\mathrm{mM}^{-1} \mathrm{~s}^{-1}\right]$ & $r_{2}\left[\mathrm{mM}^{-1} \mathrm{~s}^{-1}\right]$ & $r_{2} / r_{1}$ \\
\hline NP-OA & $25.3 \pm 0.8$ & $74.8 \pm 2.2$ & $3.0 \pm 0.2$ \\
\hline $\mathrm{NP}-\mathrm{Pn}_{3}-\mathrm{dPG}-\mathrm{OH}$ & $7.2 \pm 0.1$ & $22.2 \pm 0.1$ & $3.1 \pm 0.1$ \\
\hline NP- $\mathrm{Pn}_{3}-\mathrm{dPG}-\mathrm{OSO}_{3}{ }^{-} \mathrm{Na}^{+}$ & $8.0 \pm 0.1$ & $23.4 \pm 0.1$ & $2.9 \pm 0.1$ \\
\hline Resovist ${ }^{\circledR}$ & $7.2 \pm 0.1$ & $82.0 \pm 6.2$ & $11.4 \pm 1.0$ \\
\hline
\end{tabular}

${ }^{a}$ The relaxivity $\left(r_{1}\right.$ or $\left.r_{2}\right)$ is defined as the change in relaxation rate $\left(r_{1,2}=\right.$ $\left.1 / T_{1,2}\right)$ in units of $\mathrm{s}^{-1}$ upon addition of the contrast agent, normalized to the concentration of the contrast agent (Fe concentration in units of $\mathrm{mM})$.

extension of the collapsed polyglycerol ligands in vacuum. Note that the interparticle distance of sample NP-OA (Fig. 1(a)) is much smaller so that the particles are almost touching in dried state, which is due to the much smaller extension of the oleic acid ligand (molar mass: $282.46 \mathrm{~g} \mathrm{~mol}^{-1}$ ).

The nanoparticles of the samples NP- $\mathrm{Pn}_{3}-\mathrm{dPG}-\mathrm{OH}$, and NP$\mathrm{Pn}_{3}$-dPG-OSO ${ }_{3}{ }^{-} \mathrm{Na}^{+}$exhibit also excellent stability in physiological media, such as isotonic saline and DMEM/FCS/P/S (see Table 2). Isotonic saline acts as a simple imitation of cell media and blood because of its identical osmolarity. Aggregation of nanoparticles can occur easily in these media since their ionic strength is rather high. The ionic strength of isotonic saline $\left(154 \mathrm{mmol} \mathrm{L}^{-1}\right)$ is lower than that of DMEM/FCS/P/S $(168 \mathrm{mmol}$ $\left.\mathrm{L}^{-1}\right)$. In DMEM/FCS/P/S the hydrodynamic diameters of the samples $\mathrm{NP}-\mathrm{Pn}_{3}-\mathrm{dPG}-\mathrm{OH}$ and $\mathrm{NP}-\mathrm{Pn}_{3}-\mathrm{dPG}-\mathrm{OSO}_{3}{ }^{-} \mathrm{Na}^{+}$remain practically unchanged for 9 and 11 days, respectively, indicating

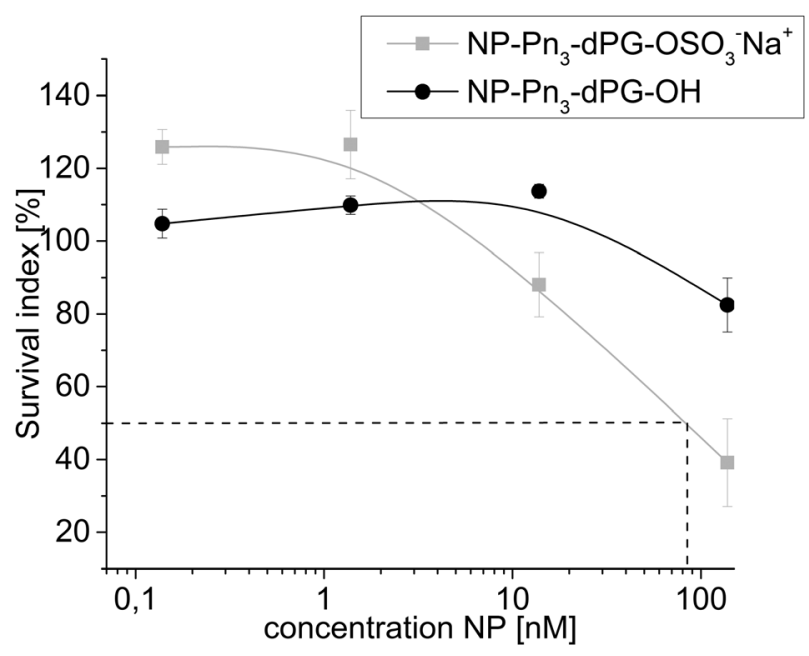

Fig. 2 Cytotoxicity of NP-Pn $-\mathrm{dPG}-\mathrm{OH}$ (black) and NP-Pn $-\mathrm{dPG}-$ $\mathrm{OSO}_{3}{ }^{-} \mathrm{Na}^{+}$(gray) in HUVECs. The HUVECs (5000 cells per well) were exposed to different concentrations of the nanoparticles for $48 \mathrm{~h}$. Viable cells were quantified in an assay employing 3-(4,5-dimethylthiazol-2-yl)-2,5-diphenyltetrazolium bromide (MTT). The survival index was calculated as the percentage of living cells after treatment in relation to untreated cells. Data are presented as mean \pm standard error of the mean of three independent experiments. The data points are connected with a B-spline to guide the eye. 
an excellent colloidal stability of both systems. In isotonic saline the hydrodynamic diameters of the same particles remain unchanged for slightly shorter periods of 4 and 5 days, accordingly. The differences between the stabilities in isotonic saline and DMEM/FCS/P/S might be explained by protein adsorption on the surface of the nanoparticles leading to more shielded and thus, more stabilized nanoparticles. ${ }^{\mathbf{4 3 , 4 4}}$ Note, that the hydrodynamic diameter of the samples NP-Pn ${ }_{3}-\mathrm{dPG}-\mathrm{OH}$ and NP-Pn ${ }_{3}-$ dPG-OSO $_{3}{ }^{-} \mathrm{Na}^{+}$are in DMEM/FCS/P/S smaller than in water demonstrating the high stability of these systems in this medium. DLS measurements of DMEM/FCS/P/S without nanoparticles yield a hydrodynamic diameter of $(39 \pm 2) \mathrm{nm}$ with a broad size distribution. ${ }^{5}$ Please note also that in the blood stream additional aggregation effects due to the shear flow or the interaction with blood cells might occur.

The magnetic properties of the samples which are responsible for the expected contrasting effect in MRI are investigated before and after ligand exchange. This is done to verify if the surface exchange strongly affects the magnetic relaxivity of iron oxide nanoparticles. Jun et al. studied systematically the relation between size, magnetism, and relaxation of iron oxide nanoparticles and showed the dependence of magnetic relaxivity of the diameter of the nanoparticles. ${ }^{45}$ Although magnetism is an intrinsic property of bulk material, the relaxivity properties of nanoparticles strongly depend on size, crystallinity, shape, and surface properties of the core and the oxidation state of the iron.,45,46 Therefore, a ligand exchange process can affect the magnetic relaxivity of iron oxide nanoparticles. ${ }^{5,47,48}$ The measurements were carried out by measuring $\mathrm{T}_{1}$ - and $\mathrm{T}_{2}$-relaxation times in chloroform (NP-OA) and ultrapure water $\left(\mathrm{NP}-\mathrm{Pn}_{3}-\mathrm{dPG}-\mathrm{OH}\right.$ and $\mathrm{NP}-\mathrm{Pn}_{3}-\mathrm{dPG}-$ $\mathrm{OSO}_{3}{ }^{-} \mathrm{Na}^{+}$) at $0.94 \mathrm{~T}$ (see Table 3).

The transversal relaxivity $r_{2}$ and the longitudinal relaxivity $r_{1}$ of the sample NP-OA in chloroform is by about a factor of three higher than the corresponding values of samples NP-Pn ${ }_{3}-\mathrm{dPG}^{-}$ $\mathrm{OH}$ and $\mathrm{NP}-\mathrm{Pn}_{3}-\mathrm{dPG}-\mathrm{OSO}_{3}{ }^{-} \mathrm{Na}^{+}$in ultrapure water. This reduction indicates that the ligand exchange influences the relaxivity. Possibly, also the changed accessibility of water to the surface is due to the bulky polyglycerol ligand shell that influences the relaxivity of the particles. ${ }^{49}$ However, particles with an $r_{2}$ value above $20 \mathrm{mM}^{-1} \mathrm{~s}^{-1}$ are well-suitable for contrast rich MRI. ${ }^{50} \mathrm{In}$ contrast to the results for $r_{2}$, the ratio $r_{2} / r_{1}$ remains constant within the experimental error during the ligand exchange process. This ratio allows a quantification of the relative contribution of the longitudinal and transversal relaxivity. As the hydrodynamic diameter of iron oxide nanoparticles

a.
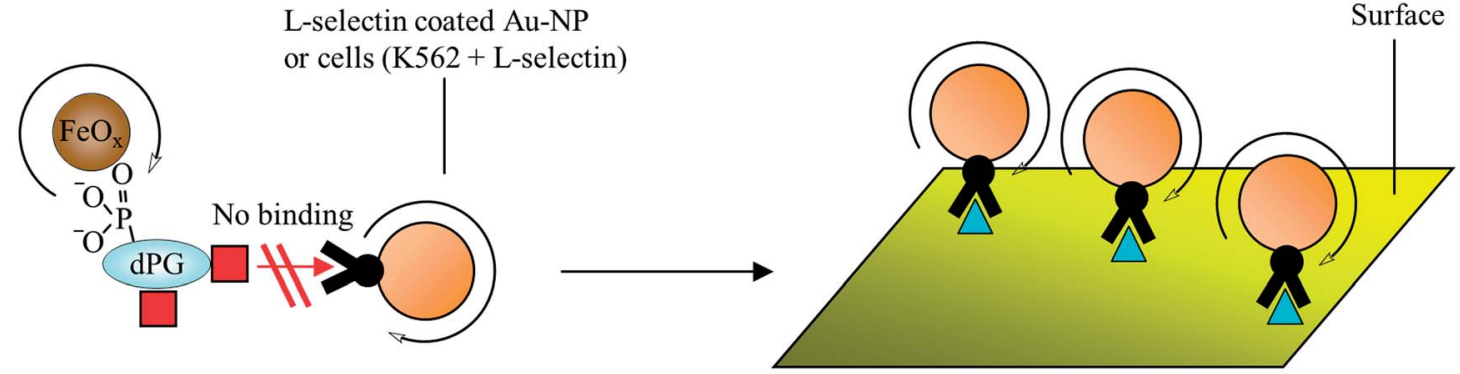

$100 \%$ binding, positive control, no inhibition

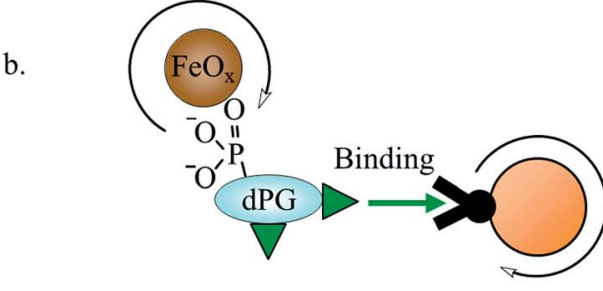

$(100-\mathrm{X}) \%$ binding of positive control inhibition

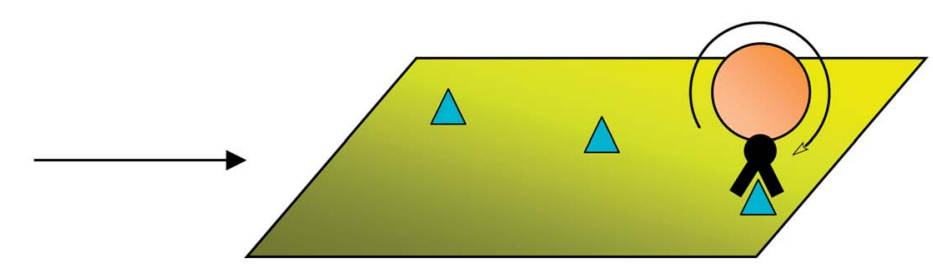

$\mathrm{X} \%$ binding of positive control inhibition

$\measuredangle=\mathrm{OSO}_{3}{ }^{-} \mathrm{Na}^{+}$groups, $\square=$ OH-groups, $\angle$ L-selectin, $\triangle=$ L-selectin ligand

Fig. 3 Schematic representation of L-selectin ligand binding studies with the synthesized nanoparticles ((a) sample NP-Pn $-\mathrm{dPG}-\mathrm{OH}$ and (b) sample NP- $\mathrm{Pn}_{3}-\mathrm{dPG}-\mathrm{OSO}_{3}{ }^{-} \mathrm{Na}^{+}$) as competitors. On the left hand side preincubation of functionalized FeO ${ }_{x}$ nanoparticles with $\mathrm{L}$-selectin carriers (Au NP or leukocytes) is shown. As a result, distinct binding to immobilized ligands on surfaces (SPR sensor chip or bottom of flow chamber) is illustrated on the right hand side. In detail, NP-Pn $n_{3}-\mathrm{dPG}-\mathrm{OH}$ or $\mathrm{NP}-\mathrm{Pn}_{3}-\mathrm{dPG}-\mathrm{OSO}{ }_{3}{ }^{-} \mathrm{Na}^{+}$were separately preincubated with L-selectin coated gold nanoparticles (Au-NP) or bare Au-NP, and subsequently passed over an SPR sensor chip carrying L-selectin ligands. In a second experiment, the nanoparticles were separately preincubated with $\mathrm{K} 562+\mathrm{L}$-selectin or $\mathrm{K} 562$ - L-selectin cells and then passed through a ligand-coated flow channel. L-selectin dependent cell binding to the ligand coated surface slows down their velocity which can be visualized as cell rolling. In the absence of NP-Pn$-\mathrm{P}_{3}-\mathrm{dPG}-\mathrm{OSO}_{3}{ }^{-} \mathrm{Na}^{+}$, the number of rolling $\mathrm{K} 562+\mathrm{L}$-selectin cells was set to $100 \%$ and reflects no inhibition. After preincubation of the cells with defined concentrations of samples NP-Pn ${ }_{3}-\mathrm{dPG}-\mathrm{OH}$ and NP-Pn${ }_{3}-\mathrm{dPG}_{-} \mathrm{OSO}_{3}{ }^{-} \mathrm{Na}^{+}$as $\mathrm{competitors}$ the number of rolling cells were counted and calculated as \% inhibition of the control. 
correlates with the ratio $r_{2} / r_{1}$, one has to normalize this ratio to the hydrodynamic radius. The normalized $r_{2} / r_{1}$ values of the water-dispersible particles $\left(\mathrm{NP}-\mathrm{Pn}_{3}-\mathrm{dPG}-\mathrm{OH}\right.$ and $\mathrm{NP}-\mathrm{Pn}_{3}-\mathrm{dPG}-$ $\mathrm{OSO}_{3}{ }^{-} \mathrm{Na}^{+}$) reaches $63 \%$ and $65 \%$ respectively, of the value of the clinically approved iron oxide contrast agent Resovist ${ }^{\circledR}$ (Bayer Schering Pharma AG). If small iron oxide nanoparticlecores are dispersed as agglomerates the $r_{2}$ and therefore the $r_{2} / r_{1}$-value is increasing drastically. In contrast to Resovist ${ }$, the samples $\mathrm{NP}-\mathrm{Pn}_{3}-\mathrm{dPG}-\mathrm{OH}$ and $\mathrm{NP}-\mathrm{Pn}_{3}-\mathrm{dPG}-\mathrm{OSO}_{3}{ }^{-} \mathrm{Na}^{+}$are not aggregated as it is clearly proven by DLS and TEM results (Fig. 1, Tables 1 and 3).

In conclusion, the results of the physico-chemical characterization indicate that the presented water-dispersible iron oxide nanoparticles are suitable as contrast agent for MRI.

Cell viability of primary human umbilical vein endothelial cells (HUVECs) was determined after $48 \mathrm{~h}$ incubation with the nanoparticles NP-Pn 3 -dPG-OH and $\mathrm{NP}-\mathrm{Pn}_{3}-\mathrm{dPG}-\mathrm{OSO}_{3}{ }^{-} \mathrm{Na}^{+}$ using a 3-(4,5-dimethylthiazol-2-yl)-2,5-diphenyltetrazolium bromide (MTT) assay. $^{51}$ Fig. 2 shows that NP-Pn ${ }_{3}-\mathrm{dPG}$ $\mathrm{OSO}_{3}{ }^{-} \mathrm{Na}^{+}$have an effect of the viability of the HUVECs after 48 $\mathrm{h}$ with a survival index $\mathrm{SI}_{50}$ corresponding to $50 \%$ of approximately $85 \mathrm{nM}$ nanoparticles (corresponding to $2.4 \mathrm{mM} \mathrm{Fe}$ ).

In the measuring range no $\mathrm{SI}_{50}$ value is reached for the NP$\mathrm{Pn}_{3}$-dPG-OH. Wu et al. found for the viability of HUVECs after $24 \mathrm{~h}$ of incubation with citrate or dextran-coated iron oxide nanoparticles $\mathrm{SI}_{50}$ values significantly below $1 \mathrm{mM} \mathrm{Fe} .^{52}$

An essential physiological reaction of inflammation is the recruitment and extravasation of leukocytes from the blood stream to inflammatory sites. ${ }^{53}$ The selectins are cell adhesion molecules involved in low affinity, but essential ligand recognition on the respected surfaces. ${ }^{54}$ Although being essential for immune surveillance, under pathophysiological conditions (e.g. chronic inflammatory diseases) massive leukocyte extravasation is often accompanied with unwanted secondary tissue damage. Recently, it was shown that dendritic polyglycerol sulfate (dPGS) has a high binding affinity towards L- and P-selectin and reduces leukocyte extravasation. ${ }^{31}$ In vitro studies using surface plasmon resonance (SPR) measurements reveal that dPGS strongly inhibits selectin ligand binding with $\mathrm{IC}_{50}$ values in the nanomolar range. ${ }^{31-33}$ In contrast, non-sulfated dendritic polyglycerol does not influence selectin binding. ${ }^{31-33}$ Therefore, binding studies were carried out with the synthesized nanoparticles (samples NP-Pn ${ }_{3}-\mathrm{dPG}-\mathrm{OH}$ and NP-Pn ${ }_{3}-\mathrm{dPG}-\mathrm{OSO}_{3}{ }^{-} \mathrm{Na}^{+}$) as competitors to evaluate their inhibitory potential. An overview of the general scenario is given in Fig. 3 .

We first measured binding by surface plasmon resonance, where a defined concentration of L-selectin coated gold NP was passed over the sensor chip, functionalized with a common synthetic L-selectin ligand polymer. The resulting signal intensity, given in resonsance units, was set to $100 \%$ binding and referred to as the positive control. ${ }^{31}$ L-selectin coated gold NP were then pre-incubated with increasing concentrations of the functionalized iron oxide nanoparticles as binding competitors and subsequently passed over the ligand carrying sensor chip. A reduction of the resonance units indicates binding of the competitor (here NP-Pn ${ }_{3}-\mathrm{dPG}-\mathrm{OSO}_{3}{ }^{-} \mathrm{Na}^{+}$) to the L-selectin coated gold NP and result in shielding. The obtained resonance units at defined competitor concentration were then calculated as \% inhibition compared to the control. The $\mathrm{IC}_{50}$ value corresponds to the competitor concentration at which $50 \%$ inhibition of the control is observed. The results reveal that in case of sample NP-Pn ${ }_{3}-\mathrm{dPG}^{-} \mathrm{OSO}_{3}{ }^{-} \mathrm{Na}^{+}$the L-selectin binding is strongly inhibited, corresponding to an $\mathrm{IC}_{50}$ value in the picomolar range. In contrast, in the case of sample NP-Pn ${ }_{3}-\mathrm{dPG}^{-}$ $\mathrm{OH}$ no inhibition is observed at the respective concentrations (see Fig. 4a). L-selectin dependent binding specificity is demonstrated with the negative control where bare gold nanoparticles incubated with the highest $\mathrm{NP}-\mathrm{Pn}_{3}-\mathrm{dPG}-\mathrm{OSO}_{3}{ }^{-} \mathrm{Na}^{+}$ concentration showed no ligand binding at all.

In order to test the efficacy of NP-Pn $3-\mathrm{dPG}^{-} \mathrm{OSO}_{3}{ }^{-} \mathrm{Na}^{+}$as L-selectin inhibitor under more physiological conditions, the nanoparticles have been applied in a cellular based flow chamber assay (Fig. 4b).$^{55-57}$ This assay mimics the capture of leukocytes from the blood stream to the vascular endothelium which is a prerequisite for subsequent leukocyte adhesion and transmigration to inflamed tissue lying underneath. In case of inflammation vascular endothelia express L-selectin ligands on the surface to catch leukocytes and slow down their velocity which can be visualized as leukocyte rolling. Therefore, the leukocyte tumor cell line K562, which does not express L-selectin (K562 - L-selectin) and the L-selectin expressing cell line (K562 + L-selectin), were passed through a ligand-coated flow channel. The number of rolling K562 + L-selectin cells was set to $100 \%$ and reflects no inhibition. After preincubation of
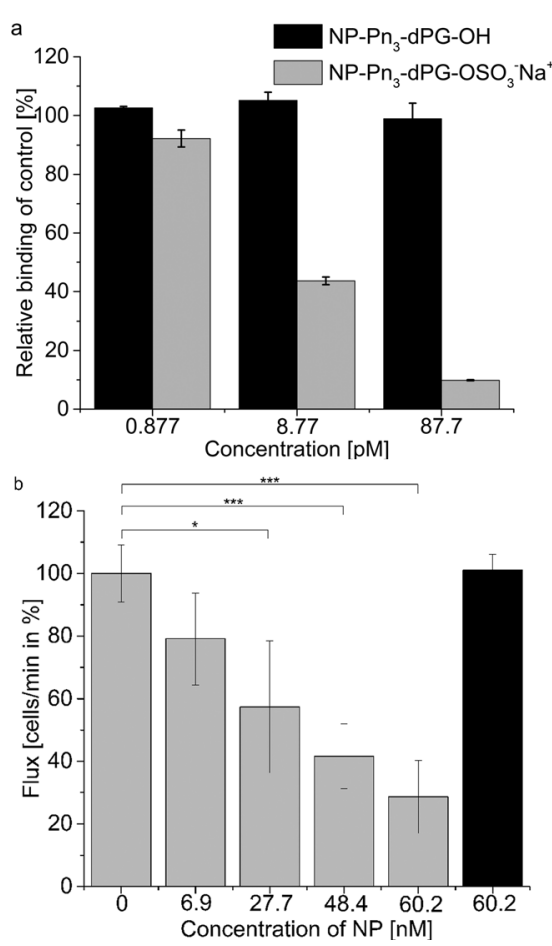

Fig. 4 (a) Competitive inhibition of $\mathrm{L}$-selectin ligand binding by $\mathrm{NP}-\mathrm{Pn}_{3}-\mathrm{dPG}-\mathrm{OH}$ (black) and $\mathrm{Pn}_{3}-\mathrm{dPG}-\mathrm{OSO}_{3}{ }^{-} \mathrm{Na}^{+}$(gray) measured by SPR. (b) NP-Pn $-n_{3}-d P G-O S O_{3}{ }^{-} \mathrm{Na}^{+}$and NP-Pn $3-d P G-O H$ measured via a flow chamber assay. ${ }^{*}, p=0.0251 ; * * *, p \leq 0.0005$ (paired $t$ test, $n=3$ ). 
the cells with defined concentrations of samples NP-Pn ${ }_{3}$-dPG$\mathrm{OH}$ and $\mathrm{NP}-\mathrm{Pn}_{3}{ }^{-} \mathrm{dPG}-\mathrm{OSO}_{3}{ }^{-} \mathrm{Na}^{+}$as competitors the number of rolling cells were counted and calculated as \% inhibition of the control (for representative movies see ESI $\dagger$ ). Fig. $4 \mathrm{~b}$ confirms a strong shielding effect of the competitor NP-Pn ${ }_{3}$-dPG-OSO ${ }_{3}{ }^{-} \mathrm{Na}^{+}$ on ligand interaction of $\mathrm{K} 562+\mathrm{L}$-selectin with an $\mathrm{IC}_{50}$ value of about $36 \mathrm{nM}$ (see also Fig. S1†). Again, NP-Pn ${ }_{3}$-dPG-OH applied at the highest concentration had no influence on ligand recognition (no inhibition). Receptor specificity was demonstrated when we used the cell line K562 - L-selectin as a negative control, where no cell rolling was observed. Please note, that the cytotoxicity was monitored after $48 \mathrm{~h}$ of continuous static incubation, whereas the cell rolling experiments depict the instant cellular binding recorded within minutes. In summary, these results indicate the potential of NP-Pn 3 - $\mathrm{dPG}-\mathrm{OSO}_{3}{ }^{-} \mathrm{Na}^{+}$to bind L-selectin on leukocytes and P-selectin on activated inflammatory endothelia and consequently, their applicability as a selective binding contrast agent in MRI.

\section{Conclusions}

Initially hydrophobic monodisperse iron oxide nanoparticles are functionalized by dendritic polyglycerol and dendritic polyglycerol sulfate ligands via simple one pot ligand exchange reactions. The obtained systems are promising candidates for selective MRI, since polyglycerol sulfate can address inflamed tissue. The polyglycerol ligands are statistically functionalized by about one or three phosphonate groups acting as linkers to iron. Dynamic light scattering and TEM measurements reveal that only the trivalent phosphonate ligands lead to colloidally stable hydrophilic nanoparticles, whereas the monovalent ligands yields particles which significantly aggregate in water. This observation can be explained by the significantly higher binding affinity of the multivalent ligand compared to the monovalent one. Iron oxide functionalized with the trivalent dendritic sulfated or non-sulfated polyglycerol ligands are colloidally stable for more than one year in ultrapure water, for several days in a cell culture medium, as well as isotonic saline. The hydrodynamic diameter of both systems is below $30 \mathrm{~nm}$ in all aqueous media under study and thus far below the diameter of nanoparticle based MRI contrast agents, which have been used clinically. The potential of the novel particles for applications as MRI contrast agent is proofed with respect to efficacy by measurements of the magnetic relaxivity of the functionalized iron oxide nanoparticles. The initially high $r_{2}$ value of the iron oxide nanoparticles is reduced during the ligand exchange reaction but it is still comparable to the values of nanoparticle based MRI contrast agents. Furthermore, only a slight cytotoxicity is observed when the nanoparticles are incubated with HUVECs after $48 \mathrm{~h}$ and no acute toxicity is found. Therefore, the particles seem to be biocompatible at the cellular level on the conditions applied. Surface plasmon resonance (SPR) studies indicate that the polyanionic dendritic polyglycerol sulfate functionalized iron oxide nanoparticles lead to an exceptional inhibition of L-selectin ligand binding, whereas the particles bearing neutral dendritic polyglycerol do not show this effect. Experiments under more physiological conditions in a flow chamber with human myelogenous leukemia cells confirmed L-selectin inhibition of NP-Pn ${ }_{3}-\mathrm{dPG}^{-} \mathrm{OSO}_{3}{ }^{-} \mathrm{Na}^{+}$and with that the L-selectin mediated leukocyte adhesion. In conclusion, novel selectively binding MRI contrast agents are developed. Their small hydrodynamic diameter makes these systems especially attractive for applications, such as lymph-node imaging, ${ }^{15,16}$ angiography, ${ }^{4}$ or functional MRI (f-MRI). ${ }^{4}$ The particles will soon be tested in in vivo studies.

\section{Acknowledgements}

This project was supported by the SPP 1313 (project NanoSelect RU 420/9-2), the Focus Area Nanoscale of the Freie Universität Berlin, the SFB 765 (projects A4, A6, B7, C5), and the Charite Universitätsmedizin Berlin. We thank Dr H. Renz and Prof. Dr R. J. Radlanski (Department of Craniofacial Developmental Biology, Charité-Universitätsmedizin Berlin) for the use of their electron microscope.

\section{Notes and references}

1 D. D. Awschalom and D. P. Divincenzo, Phys. Today, 1995, 48, 43-48.

2 P. Li, D. E. Miser, S. Rabiei, R. T. Yadav and M. R. Hajaligol, Appl. Catal., B, 2003, 43, 151-162.

3 S. Laurent, S. Dutz, U. O. Haefeli and M. Mahmoudi, Adv. Colloid Interface Sci., 2011, 166, 8-23.

4 H. B. Na, I. C. Song and T. Hyeon, Adv. Mater., 2009, 21, 2133-2148.

5 A. Hofmann, S. Thierbach, A. Semisch, A. Hartwig, M. Taupitz, E. Rühl and C. Graf, J. Mater. Chem., 2010, 20, 7842-7853.

6 R. Massart, IEEE Trans. Magn., 1981, 17, 1247-1248.

7 J. C. Bacri, R. Perzynski, D. Salin, V. Cabuil and R. Massart, J. Magn. Magn. Mater., 1986, 62, 36-46.

8 S. H. Sun, H. Zeng, D. B. Robinson, S. Raoux, P. M. Rice, S. X. Wang and G. X. Li, J. Am. Chem. Soc., 2004, 126, 273-279.

9 L. M. Bronstein, X. Huang, J. Retrum, A. Schmucker, M. Pink, B. D. Stein and B. Dragnea, Chem. Mater., 2007, 19, 36243632 .

10 E. Amstad, M. Textor and E. Reimhult, Nanoscale, 2011, 3, 2819-2843.

11 C. W. Jung and P. Jacobs, Magn. Reson. Imaging, 1995, 13, 661-674.

12 K. Hervé, L. Douziech-Eyrolles, E. Munnier, S. CohenJonathan, M. Souce, H. Marchais, P. Limelette, F. Warmont, M. L. Saboungi, P. Dubois and I. Chourpa, Nanotechnology, 2008, 19, 465608.

13 E. Amstad, S. Zurcher, A. Mashaghi, J. Y. Wong, M. Textor and E. Reimhult, Small, 2009, 5, 1334-1342.

14 A. S. Goldmann, C. Schoedel, A. Walther, J. Yuan, K. Loos and A. H. E. Mueller, Macromol. Rapid Commun., 2010, 31, 1608-1615.

15 M. G. Harisinghani, J. Barentsz, P. F. Hahn, W. M. Deserno, S. Tabatabaei, C. Hulsbergen van de Kaa, J. de la Rosette and R. Weissleder, New. Engl. J. Med., 2003, 348, 2491-2499.

16 C. Li, Nat. Mater., 2014, 13, 110-115. 
17 H. W. Gu, K. M. Xu, Z. M. Yang, C. K. Chang and B. Xu, Chem. Commun., 2005, 4270-4272.

18 J. Xie, K. Chen, J. Huang, S. Lee, J. Wang, J. Gao, X. Li and X. Chen, Biomaterials, 2010, 31, 3016-3022.

19 H. Zhou, J. H. Stafford, R. R. Hallac, L. Zhang, G. Huang, R. P. Mason, J. Gao, P. E. Thorpe and D. Zhao, J. Biomed. Nanotechnol., 2014, 10, 846-855.

20 L. Wang, Z. Yang, J. Gao, K. Xu, H. Gu, B. Zhang, X. Zhang and B. Xu, J. Am. Chem. Soc., 2006, 128, 13358-13359.

21 J. Khandare, M. Calderon, N. M. Dagia and R. Haag, Chem. Soc. Rev., 2012, 41, 2824-2848.

22 M. Calderon, M. A. Quadir, S. K. Sharma and R. Haag, Adv. Mater., 2010, 22, 190-218.

23 M. Weinhart, I. Grunwald, M. Wyszogrodzka, L. Gaetjen, A. Hartwig and R. Haag, Chem.-Asian J., 2010, 5, 1992-2000.

24 C. Siegers, M. Biesalski and R. Haag, Chem.-Eur. J., 2004, 10, 2831-2838.

25 M. Weinhart, T. Becherer and R. Haag, Chem. Commun., 2011, 47, 1553-1555.

26 T. Heek, C. Fasting, C. Rest, X. Zhang, F. Wuerthner and R. Haag, Chem. Commun., 2010, 46, 1884-1886.

27 X. Gao, X. Zhang, Z. Wu, X. Zhang, Z. Wang and C. Li, J. Controlled Release, 2009, 140, 141-147.

28 I. Papp, C. Sieben, K. Ludwig, M. Roskamp, C. Böttcher, S. Schlecht, A. Herrmann and R. Haag, Small, 2010, 6, 2900-2906.

29 T. Gillich, E. M. Benetti, E. Rakhmatullina, R. Konradi, W. Li, A. Zhang, A. D. Schlueter and M. Textor, J. Am. Chem. Soc., 2011, 133, 10940-10950.

30 H. Türk, R. Haag and S. Alban, Bioconjugate Chem., 2004, 15, 162-167.

31 J. Dernedde, A. Rausch, M. Weinhart, S. Enders, R. Tauber, K. Licha, M. Schirner, U. Zugel, A. von Bonin and R. Haag, Proc. Natl. Acad. Sci. U. S. A., 2010, 107, 19679-19684.

32 M. Weinhart, D. Groeger, S. Enders, S. B. Riese, J. Dernedde, R. K. Kainthan, D. E. Brooks and R. Haag, Macromol. Biosci., 2011, 11, 1088-1098.

33 M. Weinhart, D. Groeger, S. Enders, J. Dernedde and R. Haag, Biomacromolecules, 2011, 12, 2502-2511.

34 K. Oishi, Y. Hamaguchi, T. Matsushita, M. Hasegawa, N. Okiyama, J. Dernedde, M. Weinhart, R. Haag, T. F. Tedder, K. Takehara, H. Kohsaka and M. Fujimoto, Arthritis Rheum., 2014, DOI: 10.1002/art.38630.

35 U. Resch-Genger and K. Licha, Drug Discovery Today, 2011, 8, e87.

36 J. Vonnemann, N. Beziere, C. Bottcher, S. B. Riese, C. Kuehne, J. Dernedde, K. Licha, C. von Schacky, Y. Kosanke, M. Kimm, R. Meier, V. Ntziachristos and R. Haag, Theranostics, 2014, 4, 629-641.
37 L. Wang, K. G. Neoh, E. T. Kang, B. Shuter and S. C. Wang, Adv. Funct. Mater., 2009, 19, 2615-2622.

38 J. Park, K. J. An, Y. S. Hwang, J. G. Park, H. J. Noh, J. Y. Kim, J. H. Park, N. M. Hwang and T. Hyeon, Nat. Mater., 2004, 3, 891-895.

39 U. Wollina, Arch. Dermatol. Res., 1985, 277, 146.

40 A. Barnard and D. K. Smith, Angew. Chem., Int. Ed., 2012, 51, 6572-6581.

41 S. J. Parikh and J. Chorover, Langmuir, 2006, 22, 8492-8500.

42 B. C. Barja, M. I. Tejedor-Tejedor and M. A. Anderson, Langmuir, 1999, 15, 2316-2321.

43 C. Graf, Q. Gao, I. Schutz, C. N. Noufele, W. T. Ruan, U. Posselt, E. Korotianskiy, D. Nordmeyer, F. Rancan, S. Hadam, A. Vogt, J. Lademann, V. Haucke and E. Ruhl, Langmuir, 2012, 28, 7598-7613.

44 J. Khandare, A. Mohr, M. Calderon, P. Welker, K. Licha and R. Haag, Biomaterials, 2010, 31, 4268-4277.

45 Y. W. Jun, Y. M. Huh, J. S. Choi, J. H. Lee, H. T. Song, S. Kim, S. Yoon, K. S. Kim, J. S. Shin, J. S. Suh and J. Cheon, J. Am. Chem. Soc., 2005, 127, 5732-5733.

46 Y.-W. Jun, Y.-M. Huh, J.-S. Choi, J.-H. Lee, H.-T. Song, S. Kim, S. Yoon, K.-S. Kim, J.-S. Shin, J.-S. Suh and J. Cheon, J. Am. Chem. Soc., 2005, 127, 5732.

47 H. Duan, M. Kuang, X. Wang, Y. A. Wang, H. Mao and S. Nie, J. Phys. Chem. C, 2008, 112, 8127-8131.

48 A. G. Roca, S. Veintemillas-Verdaguer, M. Port, C. Robic, C. J. Serna and M. P. Morales, J. Phys. Chem. B, 2009, 113, 7033-7039.

49 U. I. Tromsdorf, N. C. Bigall, M. G. Kaul, O. T. Bruns, M. S. Nikolic, B. Mollwitz, R. A. Sperling, R. Reimer, H. Hohenberg, W. J. Parak, S. Forster, U. Beisiegel, G. Adam and H. Weller, Nano Lett., 2007, 7, 2422-2427.

50 A. Bertin, J. Steibel, A.-I. Michou-Gallani, J.-L. Gallani and D. Felder-Flesch, Bioconjugate Chem., 2009, 20, 760767.

51 T. Mosmann, J. Immunol. Methods, 1983, 65, 55-63.

52 X. Wu, Y. Tan, H. Mao and M. Zhang, Int. J. Nanomed., 2010, 5, 385-399.

53 S. I. Simon, M. R. Sarantos, C. E. Green and U. Y. Schaff, Clin. Exp. Pharmacol. Physiol., 2009, 36, 217-224.

54 K. Ley, Trends Mol. Med., 2003, 9, 263-268.

55 K. Buscher, S. B. Riese, M. Shakibaei, C. Reich, J. Dernedde, R. Tauber and K. Ley, J. Biol. Chem., 2010, 285, 13490-13497.

56 M. Weinhart, D. Groger, S. Enders, S. B. Riese, J. Dernedde, R. K. Kainthan, D. E. Brooks and R. Haag, Macromol. Biosci., 2011, 11, 1088-1098.

57 K. Buscher, S. B. Riese, M. Shakibaei, C. Reich, J. Dernedde, R. Tauber and K. Ley, J. Biol. Chem., 2010, 285, 1349013497. 